\title{
CFD ANALYSIS OF PELTON BUCKET
}

\section{R. PRAVEEN KUMAR}

Assistant Professor, Department of Mechanical Engineering, AMET University, Chennai, Tamilnadu, India

ABSTRACT
Pelton wheel turbine is by and large utilized for mechanical power age in hydroelectric power plant. Vibration
delivered in the framework is constrained vibration. The dynamic attributes of a hydro turbine control depend intensely
on changes in stack unsettling influences. In this way the hydro turbine shows very nonlinear, non-stationary framework
whose qualities differ fundamentally with the capricious load. At the point when the Natural recurrence of the turbine
agrees with genuine recurrence of the turbine causes the arrangement of the reverberation. This reverberation frames the
expansion in odds of disappointment of the turbine by clasping of miss hapening of the pole. The purpose of the work is
too liquid dynamic examination of Pelton can edge with a change of material in the substitution and the Physical and
mechanical properties of the ebb and flow material which is used to deliver control as a lightweight material by the drive
of data water feed. The computational fluid dynamic examination is done to choose the weight use of different materials
KEYWORDS: Pelton Wheel Turbine, Natural Recurrence \& Different Materials

Received: Oct 05, 2017; Accepted: Oct 25, 2017; Published: Jan 23, 2018; Paper Id.: IJMPERDFEB201886

\section{INTRODUCTION}

Pelton turbine utilizes the drive turbine. The Pelton turbine has water turning out at high speed from the spout. The high-speed stream strikes the containers mounted on the runner. Pelton turbine is explained by [Zoppe, B, 2006] [Zhang, Z. and Casey, M., 2007].

The striking plane bestows energy. The cans are moulded in a way to partition the stream down the middle and turn its relative speed vector about $50^{\circ}$. Pelton turbine efficiency is discussed by [Jošt, D, 2010] [Peron, 2008]. Computational Fluid Dynamics numerical prediction of Pelton turbine efficiency breaks down the impacts of the mass stream rates on the container.

The adjustments in a material with their properties are effortlessly investigated with the product. Aviation turbine fuel with spindle oil and latent heat thermal energy storage are described by [Balakrishnan, 2012] [Ponshanmugakumar, A, 2014]. The product helps to investigate minutely. The existing material of soft slush is shown. A monitoring sensor objects using mobile relay by path planning framework as in [Pravallika, A., et al. 2017]

Table 1: Obtained Zone Values

\begin{tabular}{|l|c|c|c|c|c|}
\hline \multicolumn{1}{|c|}{ Zone } & Pressure & Viscous & Total & Pressure & Total \\
\hline Wall & 542.23 & -2.3123 & 3214.25 & 2.3212 & $-3.3521 \mathrm{e}-05$ \\
\hline Plane & - & 2.2125 & -432.48 & -18.0255 & 3.338 \\
\hline
\end{tabular}

\section{PROPOSED MATERIAL}

The proposed system Computational Fluid Dynamics (CFD) consists of the materials: 
- Material

- Density

- Melting point

- $\quad$ Elastic modulus

- Poisson's ratio

- $\quad$ Tensile Strength

- Thermal Conductivity
SAE2315

$3.214 \mathrm{~g} / \mathrm{cm}^{3}$

$3412{ }^{\circ} \mathrm{C}$

145-250 Gpa

2.32

435- $564 \mathrm{Mpa}$

$45 \mathrm{~W} / \mathrm{m}-\mathrm{K}$

\section{ANALYSIS}

The simulation analysis is done using the simulator function materials SAE2315 and silicon for Pelton bucket. The simulation parameters are density, dynamic pressure, Total pressure. Silicon includes density. Ansys workbench software used to analysis the pelton wheel bucket. CFD analysis is done in this project. Computational liquid elements (CFD) is a branch of liquid mechanics that utilizations numerical investigation and information structures to take care of and break down issues that include liquid streams. PCs are utilized to play out the estimations required to recreate the connection of fluids and gasses with surfaces characterized by limit conditions. With rapid supercomputers, better arrangements can be accomplished. Continuous research yields programming that enhances the precision and speed of complex reproduction situations, for example, transonic or turbulent streams. Starting exploratory approval of such programming is performed utilizing a breeze burrow with the last approval coming in full-scale testing.

\section{SAE2315 - Density}

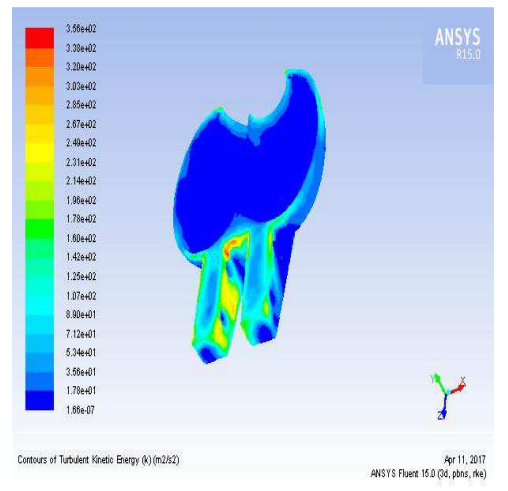

Figure 1: Density

The above figure shows the result of the pelton wheel bucket by using the ANSYS workbench software. The density of the pelton wheel bucket measured in simulation. In the figure 1 the multi colors of rectangle is showed. The colors are denote the safe and unsafe level of the pelton wheel bucket. The maximum density of the SAE2315 bucket is $3.56 \mathrm{e} 2$ and the minimum density is $1.66 \mathrm{e}-6$. The blue color in the rectangle is maximum point and the red color of the rectangle is maximum point. 


\section{SAE2315 - Dynamic Pressure}

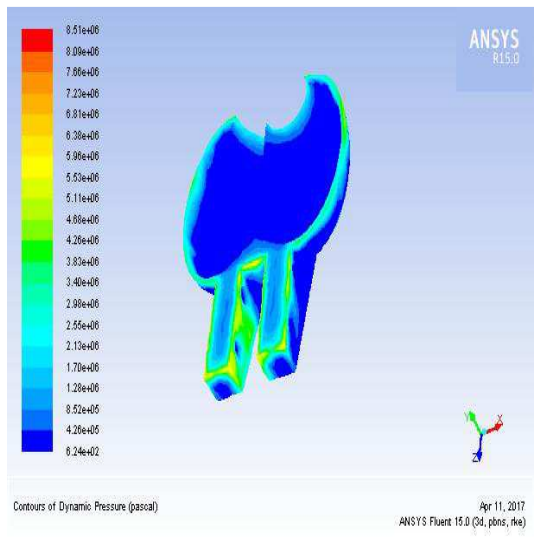

Figure 2: Dynamic Pressure

The above figure shows the result of the pelton wheel bucket by using the ANSYS workbench software. The dynamic pressure of the pelton wheel bucket measured in simulation. In the figure 2 the multi colors of rectangle is showed. The colors are denote the safe and unsafe level of the pelton wheel bucket. The maximum dynamic pressure of the SAE2315 bucket is $8.51 \mathrm{e} 6$ and the minimum dynamic pressure is $6.24 \mathrm{e} 2$. The blue color in the rectangle is maximum point and the red color of the rectangle is maximum point.

\section{SAE2315 - Total Pressure}

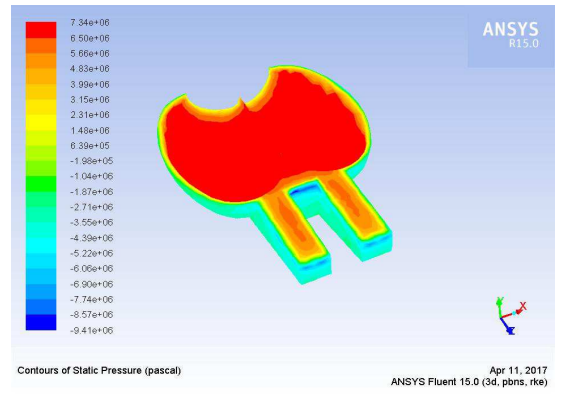

Figure 3: Total Pressure

The above figure shows the result of the pelton wheel bucket by using the ANSYS workbench software. The total pressure of the pelton wheel bucket measured in simulation. In the figure 3 the multi colors of rectangle is showed. The colors are denote the safe and unsafe level of the pelton wheel bucket. The maximum total pressure of the SAE2315 bucket is $7.34 \mathrm{e} 6$ and the minimum total pressure is $-9.41 \mathrm{e} 6$. The blue color in the rectangle is maximum point and the red color of the rectangle is maximum point.

\section{Silicon - Density}

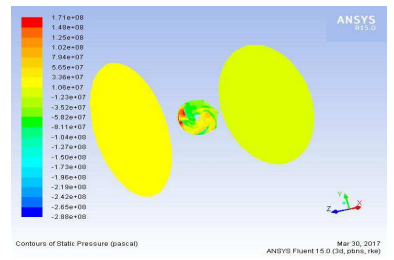

Figure 4: Silicon Density 
The above figure shows the result of the pelton wheel bucket by using the ANSYS workbench software. The density of the pelton wheel bucket measured in simulation. In the figure 4 the multi colors of rectangle is showed. The colors are denote the safe and unsafe level of the pelton wheel bucket. The maximum density of the silicon bucket is $1.71 \mathrm{e} 8$ and the minimum density is $-2.88 \mathrm{e} 8$. The blue color in the rectangle is maximum point and the red color of the rectangle is maximum point.

\section{RESULTS AND DISCUSSIONS}

Progress or hooped sprinter The plan of the hooped sprinter is planned to accomplish simple support, and the division of capacities encourages streamlining. This sprinter is made out of two half bands and cans. The meaning of the connection of the different components to each other is acquired from the burdens transmitted to the different segments. The connection of the pails is characterized in light of the radial powers and the stream stack. The container is displayed as an Inner shaft basically bolstered, laying on its focal area and subjected to a power created by a prestressed screw on the external side. The diffusive powers are totally taken up by a compound stick (pivot) settled to the loops. For the fly power, the Screw stack is duplicated by a lever arm impact in order to apply a contact heap of the basin to the edge that is significantly higher than that of the fly. The burdens transmitted to the bands are digressive and symmetrical just, the connection of the loops to each other is in this way essentially a traditional gathering utilizing studs. To aggregate up, basins are encased between two loops. By looking at the outcomes acquired from conventional and propelled container of pelton wheel we can choose the best material under given stacking conditions

\section{CONCLUSIONS}

The improvement of hooped sprinter on Pelton wheel amid the course of this work prompts the accompanying conclusions. The pelton wheels with customary pail have been demonstrated in a 3D CAD called SOLIDWORKS 2013. The pelton wheel with progressed buket has been demonstrated in a 3d Cad SOLIDWORKS. From the above outcomes, the significance passed on by the proposed material of mellow steel has the low static issues. Which in wording the high weight material gives gravity to complete revolution? Along these lines, the outcomes are plotted. The investigation completed in this undertaking is only one stage towards enhancement. There is huge extent of work in this subject. Loop improvement should be possible by parametric investigation of circle in which by shifting the thickness of band it can be accomplished. The exhaustion examination of pelton wheel should be possible. By directing trial Life cycle expectation of pelton wheel is additionally conceivable.

\section{REFERENCES}

1. Zoppe, B., Pallone, C., Maître, T. and Leroy, P., 2006. Flow analysis inside a Pelton turbine bucket. Journal of turbomachinery, 128(3), pp.500-511.

2. Zhang, Z. and Casey, M., 2007. Experimental studies of the jet of a Pelton turbine. Proceedings of the Institution of Mechanical Engineers, Part A: Journal of Power and Energy, 221(8), pp.1181-1192.

3. Jošt, D., Mežnar, P. and Lipej, A., 2010. Numerical prediction of Pelton turbine efficiency. In IOP Conference Series: Earth and Environmental Science (Vol. 12, No. 1, p. 012080). IOP Publishing.

4. Peron, M.A.R.I.O., Parkinson, E., Geppert, L. and Staubli, T., 2008, September. Importance of jet quality on Pelton efficiency and cavitation. In Proceedings of the IGHEM, International Conference on Hydraulic Efficiency Measurements, Milan, Italy, Sept (pp. 3-6). 
5. Balakrishnan, J., Ekambaram, S., Sharma, S., Ramachandran, G. Characterization of aviation turbine fuel with spindle oil, Journal of Chemical and Pharmaceutical Research 4(7), pp. 3672-3675, 2012.

6. Ponshanmugakumar, A., Sivashanmugam, M., \& Jayakumar, S. S. (2014). The solar-driven air conditioning system integrated with latent heat thermal energy storage. Indian Journal of Science and Technology, 7(11), 1798-1804.

7. Robin Thakur et al., Correlation Development for Erosive Wear Rate on Pelton Turbine Buckets, International Journal of Mechanical and Production Engineering Research and Development (IJMPERD), Volume 7, Issue 3, May - June 2017, pp. 259-275

8. Pravallika, A., et al. (2017). Monitoring sensor objects using mobile relay by path planning framework. International Journal of MC Square Scientific Research, 9, (1), 288-294. 
